\title{
Commentary
}

\section{Dietary vitamin A intake recommendations revisited: global confusion requires alignment of the units of conversion and expression}

\author{
First published online 22 March 2017
}

In 1967, the FAO and the WHO proposed a unit of dietary reference values for vitamin $\mathrm{A}$, retinol equivalents (RE), which designated $1 \mu \mathrm{g}$ of preformed vitamin $\mathrm{A}$ in the retinoid form as $1 \mu \mathrm{g} \mathrm{RE}$, and made considerations for a lower bioconversion efficiency for the provitamin A carotenoids as sources of the vitamin (Table 1$)^{(1,2)}$. Based on compelling evidence that the absorption of provitamin A carotenoids, especially from dark green leafy vegetables, is much lower than previously assumed ${ }^{(3-6)}$, the Institute of Medicine (IOM; now called the Health and Medicine Division) concluded that higher bioconversion factors were more appropriate and formulated RDA values for vitamin A using microgram retinol activity equivalents ( $\mu \mathrm{g}$ RAE) as the unit of reference in $2001^{(7)}$. This was later confirmed in follow-up studies ${ }^{(8-14)}$, which largely corroborate the current IOM policy to estimate the bioconversion factors of $\beta$-carotene from an average Western diet as 12:1 and of other provitamin A carotenoids as 24:1 (Table 1). For low- and middle-income countries, West et al. (2002) ${ }^{(15)}$ suggested an even higher conversion factor for $\beta$-carotene, namely 21:1, based on studies conducted in Asia ${ }^{(16-18)}$, which was later confirmed by other studies in other settings ${ }^{(19,20)}$. The difference in estimated conversion factors between low- and middle-income countries and Western countries can be explained by diet- and host-related factors such as food matrix, fat intake and health status ${ }^{(21)}$.

Following deliberations of micronutrient recommendations in Bangkok, Thailand in 1998, WHO/FAO published international guidelines, including those for vitamin $\mathrm{A}$ intake, in 2004, retaining the RE as the unit of reference ${ }^{(22)}$. In March 2015, the European Food Safety Authority (EFSA) updated the new European guidelines for vitamin A requirements and, surprisingly, opted to maintain the outdated conversion factors by keeping the RE as the unit of intake ${ }^{(23)}$ despite the growing evidence further

Table 1 Amount of dietary retinol $(\mu \mathrm{g})$ when expressed as retinol equivalents ( $\mu \mathrm{g} R E$ ) or retinol activity equivalents ( $\mu \mathrm{g} R A E$ )

\begin{tabular}{lrr}
\hline & RE & RAE \\
\hline Preformed retinol & 1 & 1 \\
Provitamin A & 6 & 12 \\
All-trans $\beta$-carotene & 12 & 24 \\
a-Carotene & 12 & 24 \\
-Cryptoxanthin & & \\
\hline
\end{tabular}

supporting higher conversion factors over the last decade ${ }^{(24-26)}$.

In the evaluation of adequacy of dietary vitamin A intake, two factors are important: (i) the absolute difference in recommended values between institutes; and (ii) the difference in units of expression. For lactating women, WHO recommends a daily intake of $850 \mu \mathrm{g}$ RE, whereas IOM recommends $1300 \mu \mathrm{g}$ RAE and EFSA recommends $1300 \mu \mathrm{g}$ RE (Table 2). Although the latter two recommendations will be similar when all vitamin A from the diet is derived as the preformed vitamin, these will diverge greatly when a substantial part is derived from provitamin A sources. For example, we recently compared dietary vitamin A intake of Guatemalan urban- and rural-living pregnant and lactating women with their status-specific requirements ${ }^{(27)}$. The mean intake of preformed vitamin A in the diet of lactating women from rural Guatemala was $330 \mu \mathrm{g}$, which was mostly derived from fortified sugar. Assuming that two-thirds of provitamin A intake from plant-based sources is in the form of all-trans $\beta$-carotene and one-third as other provitamin A carotenoids, these women ought to take in $4160 \mu \mathrm{g}$ of provitamin A according to the WHO/FAO Recommended Nutrient Intake recommendation ( $850 \mu \mathrm{g} \mathrm{RE}), 7760 \mu \mathrm{g}$ according to the EFSA Population Reference Intake recommendation (1300 $\mu \mathrm{g}$ $\mathrm{RE})$ and $15520 \mu \mathrm{g}$ according to the IOM RDA recommendation $(1300 \mu \mathrm{g}$ RAE; Table 3$)$. The lower the dietary intake of preformed vitamin $\mathrm{A}$, the wider the gap between the specific recommendations series becomes (Fig. 1).

Beyond these divergent recommendations, food composition tables also express total vitamin A and provitamin A content of foods as either $\mu \mathrm{g}$ RE or $\mu \mathrm{g}$ RAE. The US Department of Agriculture tables present both the preformed and provitamin A content of foods in RAE units ${ }^{(28)}$. Although devised for North America and expressed in the homologous vitamin A unit, the US Department of Agriculture tables are also used extensively in low- and middle-income countries where food composition tables are often lacking; these same countries, however, may be applying WHO requirement recommendations in RE units to assess adequacy. The same is true for European countries such as the Netherlands and Sweden, that have a food composition table based on RAE but are now confronted with EFSA recommendations expressed as RE. This mismatch in the units of comparison 
Table 2 Vitamin A intake requirements and daily recommendations as advised by the Institute of Medicine (IOM), the WHO/FAO and the European Food Safety Authority (EFSA)

\begin{tabular}{|c|c|c|c|c|c|c|}
\hline & \multicolumn{2}{|c|}{ IOM, 2001} & \multicolumn{2}{|c|}{ WHO/FAO, 2004} & \multicolumn{2}{|c|}{ EFSA, 2015} \\
\hline & EAR (RAE) & RDA (RAE) & $\mathrm{MR}(\mathrm{RE})$ & $\mathrm{RNI}(\mathrm{RE})$ & $A R(R E)$ & PRI (RE) \\
\hline Children $1-6$ years & $210-275$ & $300-400$ & 200 & $400-450$ & $205-245$ & $250-300$ \\
\hline Women, $>18$ years & 500 & 700 & 270 & 500 & 490 & 650 \\
\hline Men, >18 years & 625 & 900 & 300 & 600 & 570 & 750 \\
\hline Pregnant women & 550 & 770 & 370 & 800 & 540 & 700 \\
\hline Lactating women & 900 & 1300 & 450 & 850 & 1020 & 1300 \\
\hline
\end{tabular}

EAR, Estimated Average Requirement; RAE, retinol activity equivalents; MR, Mean Requirement; RE, retinol equivalents; RNI, Recommended Nutrient Intake; AR, Average Requirement; PRI, Population Reference Intake.

Table 3 Case example of estimated required provitamin A intake needed to fulfil the recommended daily intake for a lactating woman in rural Guatemala according to recommendations by WHO/FAO, the European Food Safety Authority (EFSA) and the Institute of Medicine (IOM)

\begin{tabular}{|c|c|c|c|c|c|c|}
\hline & \multicolumn{2}{|c|}{$\begin{array}{l}\text { WHO/FAO RNI recommendation } \\
(850 \mu \mathrm{g} \mathrm{RE})^{(22)}\end{array}$} & \multicolumn{2}{|c|}{$\begin{array}{l}\text { EFSA PRI recommendation } \\
(1300 \mu \mathrm{g} \mathrm{RE})^{(23)}\end{array}$} & \multicolumn{2}{|c|}{$\begin{array}{l}\text { IOM RDA recommendation } \\
(1300 \mu \mathrm{g} \mathrm{RAE})^{(7)}\end{array}$} \\
\hline & RE units & $\mu \mathrm{g}$ provitamin $\mathrm{A}$ & RE units & $\mu \mathrm{g}$ provitamin $\mathrm{A}$ & RAE units & $\mu \mathrm{g}$ provitamin $\mathrm{A}$ \\
\hline Retinoid & 330 & & 330 & & 330 & \\
\hline$\beta$-Carotene & 347 & 2080 & 647 & 3880 & 647 & 7760 \\
\hline Other carotenes & 173 & 2080 & 323 & 3880 & 623 & 7760 \\
\hline Total & 850 & 4160 & 1300 & 7760 & 1300 & 15520 \\
\hline
\end{tabular}

RNI, Recommended Nutrient Intake; RE, retinol equivalents; PRI, Population Reference Intake; RAE, retinol activity equivalents.

Stipulated is that the daily intake of preformed vitamin $A$ is $330 \mu g^{(27)}$, that two-thirds of provitamin $A$ intake comes from intrinsic $\beta$-carotene and that one-third comes from other provitamin A carotenes in foods.

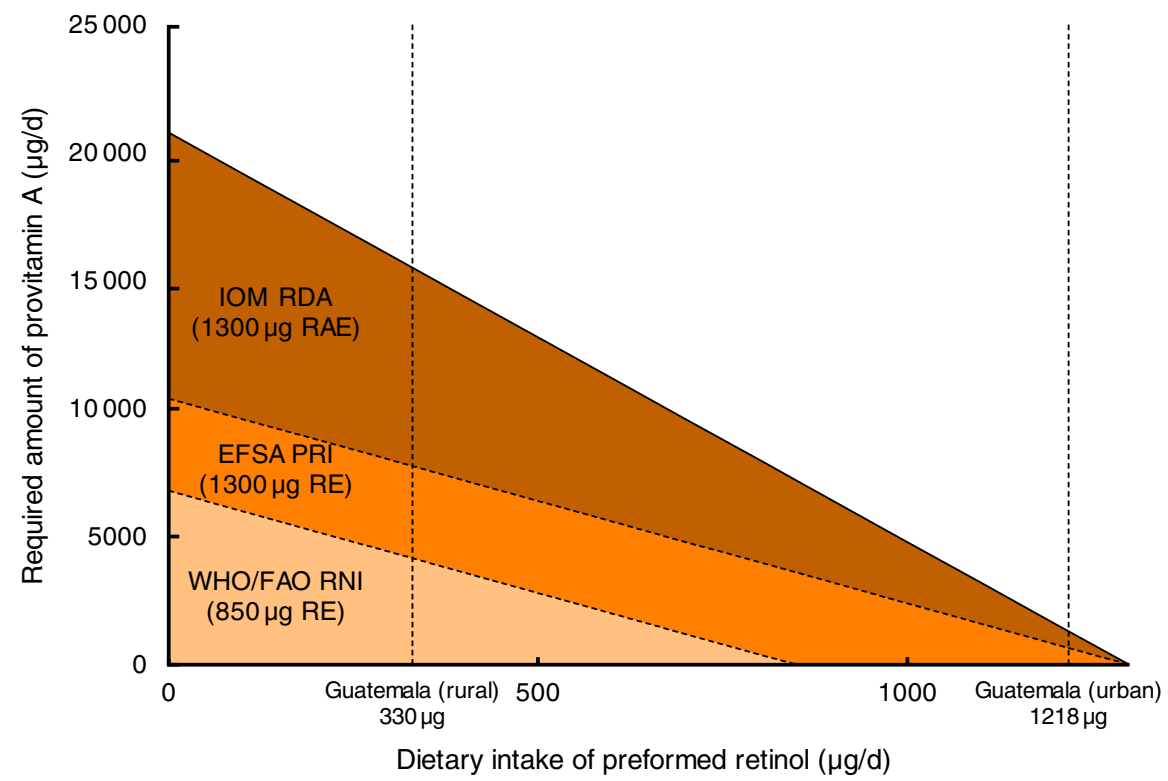

Fig. 1 Required amount of provitamin A intake for lactating women at each given preformed vitamin A intake to fulfil the recommended daily intake according to recommendations by the WHO/FAO, the European Food Safety Authority (EFSA) and the Institute of Medicine (IOM). Estimated intake of preformed vitamin A intake is $330 \mu \mathrm{g}$ for rural Guatemalan lactating women and $1218 \mu \mathrm{g}$ for urban Guatemalan lactating women ${ }^{(27)}$. It is assumed that two-thirds of provitamin A intake comes from intrinsic $\beta$-carotene and one-third from other provitamin A carotenes in foods (RAE, retinol activity equivalents; PRI, Population Reference Intake; RE, retinol equivalents; RNI, Recommended Nutrient Intake)

between ingested and required vitamin $\mathrm{A}$ intakes makes the assessment of adequacy of vitamin A intake complex, confusing and difficult to communicate.

We therefore urgently ask that an expert consultation be convened by WHO and FAO to review the evidence on bioefficacy of provitamin A carotenoids and implications for conversion factors from dietary carotenoids to retinol equivalents in order to re-establish: (i) units of measurement (expressed as retinol equivalent or retinol activity equivalent); (ii) mean requirements; (iii) Recommended Nutrient Intakes 
for preformed and provitamin A, based on differences in dietary pattern between populations; and (iv) food composition units of expression for preformed and provitamin A content. Revised conversion factors and intake recommendations could then be promoted for worldwide adoption, which would promote accuracy in assessment, a more uniform understanding and clarity in guiding populations globally towards a diet adequate in this essential nutrient.

\section{Acknowledgements}

Financial support: This research received no specific grant from any funding agency in the public, commercial or not-for-profit sectors. Conflict of interest: None of the authors have a conflict of interest. Authorship: A.M.-B. wrote the initial draft; M.V. and N.W.S. provided the data for the calculations of the Guatemalan case study; all authors have contributed to follow-up versions and have approved the final content. Ethics of buman subject participation: Not applicable.

Alida Melse-Boonstra ${ }^{1}$, Marieke Vossenaar ${ }^{2}$, Carolien A van Loo-Bouwman ${ }^{3}$, Klaus Kraemer ${ }^{4,5}$, Saskia de Pee ${ }^{6,7}$, Keith P West $\mathrm{Jr}^{5}$, Robert M Russell ${ }^{8}$ and Noel W Solomons ${ }^{2,7}$

${ }^{1}$ Division of Human Nutrition Wageningen University PO Box 81296700 EV Wageningen The Netherlands Email: alida.melse@wur.nl

${ }^{2}$ Center for Studies of Sensory Impairment, Aging and Metabolism (CeSSIAM) Guatemala City, Guatemala

${ }^{3}$ Yili R\&D Center Wageningen, The Netherlands

${ }^{4}$ Sight and Life Basel, Switzerland

${ }^{5}$ Center for Human Nutrition Department of International Health Johns Hopkins Bloomberg School of Public Health Baltimore, MD, USA

${ }^{6}$ World Food Programme Rome, Italy

${ }^{7}$ Friedman School of Nutrition Science and Policy Tufts University, Boston, MA, USA

${ }^{8}$ USDA Human Nutrition Research Center Tufts University, Boston, MA, USA

\section{References}

1. Food and Agriculture Organization of the United Nations \& World Health Organization (1967) Requirements of Vitamin A, Thiamine, Riboflavin and Niacin. Report of a Joint FAO/WHO Expert Group, Rome, Italy, 6-17 September 1965. WHO Technical Report Series no. 362. Geneva: WHO.

2. Food and Agriculture Organization of the United Nations \& World Health Organization (1988) Requirements of Vitamin A, Iron, Folate and Vitamin $B_{12}$. Joint WHO/FAO Expert Consultation. FAO Food and Nutrition Series no. 23. Rome: FAO.

3. Micozzi MS, Brown ED, Edwards BK et al. (1992) Plasma carotenoid response to chronic intake of selected foods and $\beta$-carotene supplements in men. Am J Clin Nutr $\mathbf{5 5}$, $1120-1125$.

4. Torronen R, Lehmusaho M, Hakkinen S et al. (1996) Serum $\beta$-carotene response to supplementation with raw carrots, carrot juice or purified $\beta$-carotene in healthy non-smoking women. Nutr Res 16, 565-575.

5. Castenmiller JJ, West CE, Linssen JP et al. (1999) The food matrix of spinach is a limiting factor in determining the bioavailability of $\beta$-carotene and to a lesser extent of lutein in humans. J Nutr 129, 349-355.

6. van het Hof KH, Tijburg LB, Pietrzik K et al. (1999) Influence of feeding different vegetables on plasma levels of carotenoids, folate and vitamin C. Effect of disruption of the vegetable matrix. Br J Nutr 82, 203-212.

7. Institute of Medicine (2001) Dietary Reference Intakes for Vitamin A, Vitamin K, Arsenic, Boron, Chromium, Copper, Iodine, Iron, Manganese, Molybdenum, Nickel, Silicon, Vanadium and Zinc. Washington, DC: National Academy Press.

8. Edwards AJ, You CS, Swanson JE et al. (2001) A novel extrinsic reference method for assessing the vitamin A value of plant foods. Am J Clin Nutr 74, 348-355.

9. Tang G, Qin J, Dolnikowski GG et al. (2005) Spinach or carrots can supply significant amounts of vitamin A as assessed by feeding with intrinsically deuterated vegetables. Am J Clin Nutr 82, 821-828.

10. Ghavami A, Coward WA \& Bluck LJC (2012) The effect of food preparation on the bioavailability of carotenoids from carrots using intrinsic labelling. Br J Nutr 107, 1350-1366.

11. Li L, Wang Y, Wu J et al. (2007) Bioefficacy of plant carotenoid to vitamin A in school age children. Wei Sheng Yan Јiи 36, 547-551.

12. Wang J, Wang Z, Wang Y et al. (2007) Vitamin A equivalence of spinach $\beta$-carotene in human body. Wei Sheng Yan Jiu 36, 449-453.

13. van Loo-Bouwman CA, West $\mathrm{CE}$, van Breemen $\mathrm{RB}$ et al. (2009) Vitamin A equivalency of $\beta$-carotene in healthy adults: limitation of the extrinsic dual-isotope dilution technique to measure matrix effect. $\mathrm{Br} J$ Nutr 101, 1837-1845.

14. van Loo-Bouwman CA, Naber THJ, van Breemen RB et al. (2010) Vitamin A equivalency and apparent absorption of $\beta$-carotene in ileostomy subjects using a dual-isotope dilution technique. Br J Nutr 103, 1836-1843.

15. West CE, Eilander A \& van Lieshout M (2002) Consequences of revised estimates of carotenoid bioefficacy for dietary control of vitamin A deficiency in developing countries. J Nutr 132, 9 Suppl., 2290S-2926S.

16. de Pee S, West CE, Permaesih D et al. (1998) Orange fruit is more effective than are dark-green, leafy vegetables in increasing serum concentrations of retinol and $\beta$-carotene in schoolchildren in Indonesia. Am J Clin Nutr 68, 1058-1067.

17. de Pee S, West CE, Muhilal et al. (1995) Lack of improvement in vitamin A status with increased consumption of dark-green leafy vegetables. Lancet 346, 75-81. 
18. Tang G, Gu X, Hu S et al. (1999) Green and yellow vegetables can maintain body stores of vitamin A in Chinese children. Am J Clin Nutr 70, 1069-1076.

19. Haskell MJ, Jamil KM, Hassan F et al. (2004) Daily consumption of Indian spinach (Basella alba) or sweet potatoes has a positive effect on total-body vitamin A stores in Bangladeshi men. Am J Clin Nutr 80, 705-714.

20. Khan NC, West CE, de Pee S et al. (2007) The contribution of plant foods to the vitamin A supply of lactating women in Vietnam: a randomized controlled trial. Am J Clin Nutr $\mathbf{8 5}$, $1112-1120$.

21. West CE \& Castenmiller JJ (1998) Quantification of the 'SLAMENGHI' factors for carotenoid bioavailability and bioconversion. Int J Vitam Nutr Res 68, 371-377.

22. World Health Organization \& Food and Agriculture Organization of the United Nations (2004) Vitamin and Mineral Requirements in Human Nutrition, 2nd ed. Joint FAO/WHO Expert Consultation on Human Vitamin and Mineral Requirements. Geneva: WHO.

23. European Food Safety Authority, Panel on Dietetic Products, Nutrition and Allergies (2015) Scientific opinion on dietary reference values for vitamin A. EFSA J 13, 4028, 84 pp.

24. Haskell MJ (2012) The challenge to reach nutritional adequacy for vitamin A: $\beta$-carotene bioavailability and conversion - evidence in humans. Am J Clin Nutr 96, issue 5, 1193S-1203S.

25. van Loo-Bouwman CA, Naber THJ \& Schaafsma G (2014) A review of vitamin A equivalency of $\beta$-carotene in various food matrices for human consumption. Br J Nutr 111, 2153-2166.

26. Tang G (2014) Vitamin A value of plant food provitamin A - evaluated by the stable isotope technologies. Int J Vitam Nutr Res 84, Suppl. 1, S25-S29.

27. Bielderman I, Vossenaar M, Melse-Boonstra A et al. (2016) The potential double-burden of vitamin A malnutrition: under- and over-consumption of fortified table sugar in the Guatemalan highlands. Eur J Clin Nutr 70, 947-953.

28. US Department of Agriculture (2015) USDA National Nutrient Database for Standard Reference, Release 28. http://www.ars.usda.gov/Services/docs.htm?docid=8964 (accessed March 2016). 